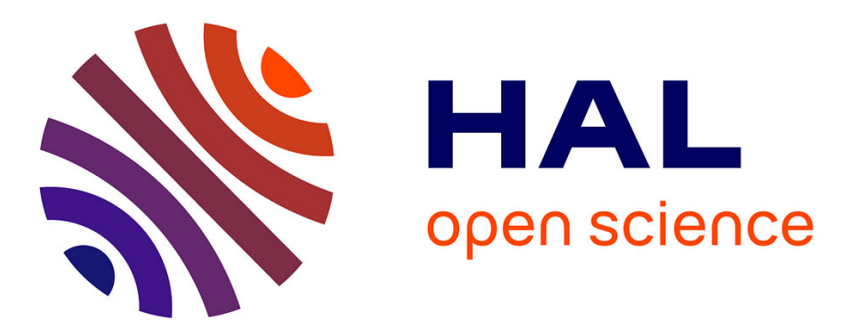

\title{
A STUDY OF THE STABILITY OF IRRADIATION INDUCED POINT DEFECTS ON VARIOUS DISLOCATION CLASSES IN COPPER AND SILVER
}

J. Lauzier, Pascal Girard, C. Minier

\section{- To cite this version:}

J. Lauzier, Pascal Girard, C. Minier. A STUDY OF THE STABILITY OF IRRADIATION INDUCED POINT DEFECTS ON VARIOUS DISLOCATION CLASSES IN COPPER AND SILVER. Journal de Physique Colloques, 1981, 42 (C5), pp.C5-247-C5-251. 10.1051/jphyscol:1981535 . jpa-00221077

\section{HAL Id: jpa-00221077 https://hal.science/jpa-00221077}

Submitted on 1 Jan 1981

HAL is a multi-disciplinary open access archive for the deposit and dissemination of scientific research documents, whether they are published or not. The documents may come from teaching and research institutions in France or abroad, or from public or private research centers.
L'archive ouverte pluridisciplinaire HAL, est destinée au dépôt et à la diffusion de documents scientifiques de niveau recherche, publiés ou non, émanant des établissements d'enseignement et de recherche français ou étrangers, des laboratoires publics ou privés. 
JOURNAL DE PHYSIQUE

Culloque C5, supplément au n¹0, Tome 42, octobre 1981

page $\mathrm{C} 5-247$

\title{
A STUDY OF THE STABILITY OF IRRADIATION INDUCED POINT DEFECTS ON VARIOUS DISLOCATION CLASSES IN COPPER AND SILVER
}

\author{
J. Lauzier ${ }^{*}$, P. Girard and C. Minier ${ }^{*}$ \\ Centre d'Études Nuetéaires de Grenoble, Département de Recherche Fondamentale \\ Section de Physique du Solide, $85 X-38041$ Grenoble Cedex, France \\ * Institut Polytechnique de Grenoble, France \\ * Université Scientifique et Médicale de Grenoble, France \\ Abstract.- The variation of the Bordoni peaks has been studied in copper and \\ silver during electron irradiation at $110 \mathrm{~K}$ and subsequent annealings up to \\ $300 \mathrm{~K}$. It is concluded that the interstitials are stable on the dislocations \\ giving rise to $B_{2}$ up to $150 \mathrm{~K}$ in the two metals. In copper they can diffuse \\ along the dislocations giving rise to $B_{1}$ for temperatures lower than $110 \mathrm{~K}$. \\ The vacancies pinn both dislocation classes up to $300 \mathrm{~K}$.
}

1. Introduction.- Internal friction and modulus measurements performed at different temperatures allow the separation of the motion of different classes of dislocations. At very low temperature the geometrical kinks are very mobile and give rise to internal friction, at a higher temperature the Bordoni peaks are usually attributed to double kink formation on different dislocation classes, in copper we have proposed (1) that $B_{2}$ is associated to dislocations lying along $\langle 110\rangle$ and $B_{1}$ along $\langle 113\rangle$.

The interstitials created by electron bombardment are freely mobile at the temperature of stage $I$, around $45 \mathrm{~K}$ in copper and $35 \mathrm{~K}$ in silver. The monovacancies migrate during the stage III between 200 and $300 \mathrm{~K}$ in the two metals.

To study the stability of point defects on the different dislocation classes in copper and silver we have performed electron bombardments at $110 \mathrm{~K}$ and measured the height of the Bordoni peaks and the internal friction and elastic modulus at $9 \mathrm{~K}$ during the irradiation and after subsequent annealings at increasing temperatures.

2. Experimental procedure.- The apparatus for an automatic measurement of the damping and elastic modulus has been described previously (2) and also the cryostat working between $8 \mathrm{k}$ and $750 \mathrm{~K}$ and the irradiation facilities (3).

The samples in form of a dual cantilever foil (resonant frequency of the order of 200 to $400 \mathrm{~Hz}$ ) are preprared from pure COMINCO copper (99.9999\%) or PURCLA silver $(99.999 \%)$, after an annealing around $900 \mathrm{~K}$ under high vacuum, they are submitted to a cold work at $10 \mathrm{k}$ by an amount of $0.5 \%$ to $3 \%$ and an annealing at $130 \mathrm{k}$.

3. Results.-

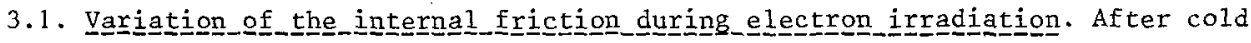
work the copper sample exhibits the two Bordoni peaks $B_{1}$ and $B_{2}$ at $32 \mathrm{~K}$ and $65 \mathrm{~K}$. We have already shown (1) the variation of the damping spectra after successive electron bombardments at $110 \mathrm{~K}$. Figure 1 shows the variation of the amplitude of $B_{1}$ and $B_{2}$ with the electron dose. $B_{2}$ decreases continuously while $B_{1}$ begins to 
increase by $25 \%$ before decreasing; the modulus anomalies associated with each peak present the same evolution. The modulus defect and the internal friction measured at $9 \mathrm{~K}$ after each irradiation decrease continuously.

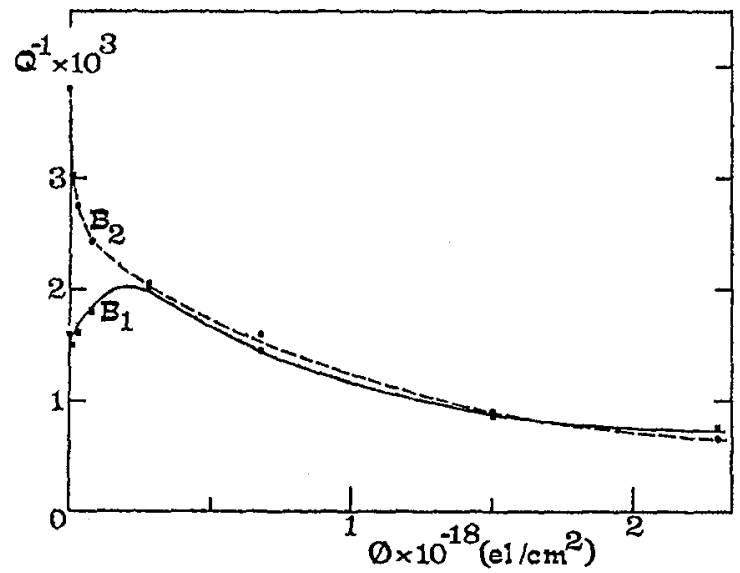

Fig. 1. Variation of the amplitudes of $B_{1}$ and $B_{2}$ in a copper sample after electron bombardment to a dose $\Phi$.

After cold work, the silver sample presents the damping spectrum shown in fig. 2.1. with the peak $B_{2}$ at $60 \mathrm{k}$ and no peak $B_{1}$, the evolution of the spectra after successive electron irradiations at $110 \mathrm{~K}$ is shown in $\mathrm{fig} .2$, the peak $\mathrm{B}_{2}$ decreases continuously while the damping and modulus defect measured at $9 \mathrm{~K}$ also decrease.

Fig. 2. Internal friction spectra of a silver sample after several irradiations at $110 \mathrm{~K}$ with the following coses $\Phi\left(\mathrm{e} 1 / \mathrm{cm}^{2}\right)$

1 - before irradiation

$2-3.10^{14} 3-8.10^{14}$

$4-50 \cdot 10^{14} \cdot 5-160.10^{14}$

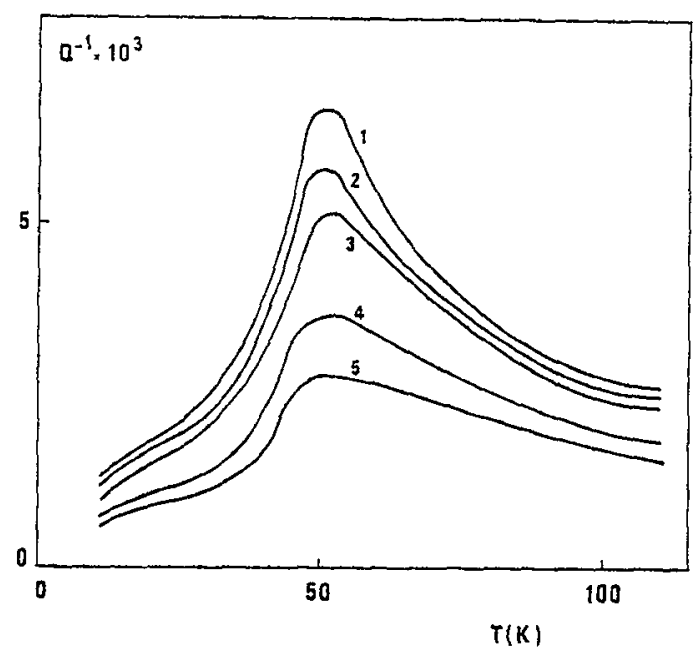

3.2. Variation of the damping during annealing treatments after irradiation. We have performed, after the last irradiation at $110 \mathrm{~K}$, isochronal annealings $\left(10 \mathrm{mn}\right.$ ) with increasing temperature $\mathrm{T}_{\text {an }}$. After each treatment the internal friction and elastic modulus are measured from $9 \mathrm{~K}$ up to $T_{\text {an }}$. Fig. 3 shows the internal 
friction spectra obtained in the copper sample after each annealing between $120 \mathrm{~K}$ and $220 \mathrm{~K}$.

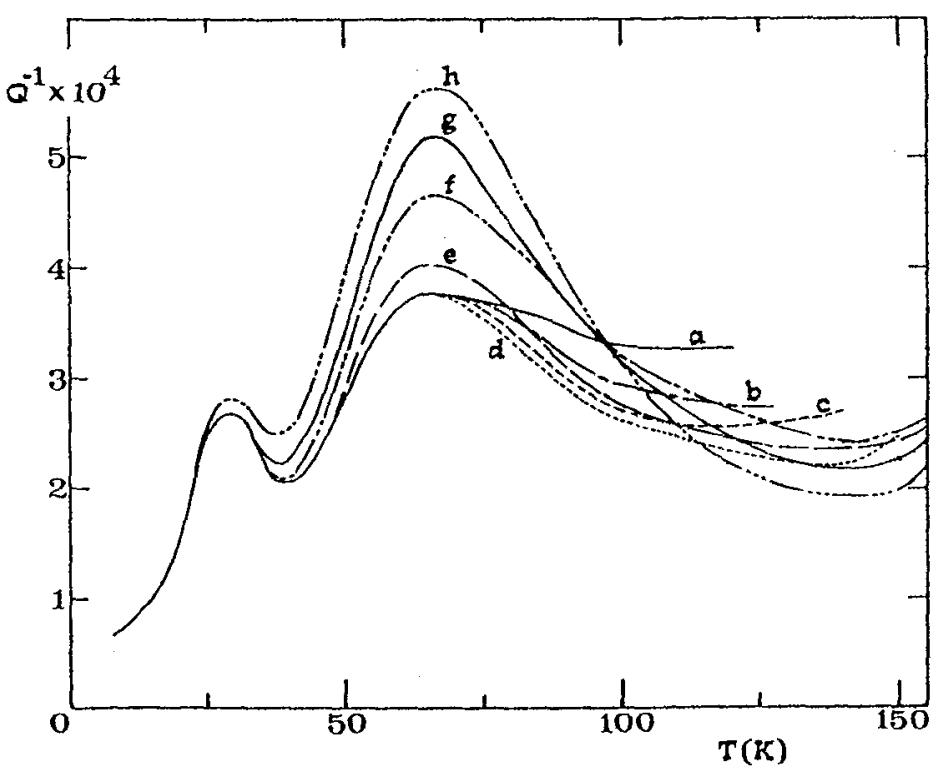

Fig. 3. Internal friction spectra of a copper sample after irradiation at $110 \mathrm{~K}$ and subsequent isochronal annealings at increasing temperatures. a) $120 \mathrm{~K}$, b) $130 \mathrm{~K}$, c) $140 \mathrm{~K}$, d) $150 \mathrm{~K}$, e) $160 \mathrm{~K}$, f) $180 \mathrm{k}$, g) $200 \mathrm{~K}$ and h) $220 \mathrm{~K}$.

Fig. 4 shows the variation of the amplitudes of $B_{1}$ and $B_{2}$ with the annealing temperature. $B_{1}$ remains almost constant up to $220 \mathrm{~K}$ and then decreases while $B_{2}$ increases between $160 \mathrm{~K}$ and $220 \mathrm{~K}$ and decreases higher temperature.

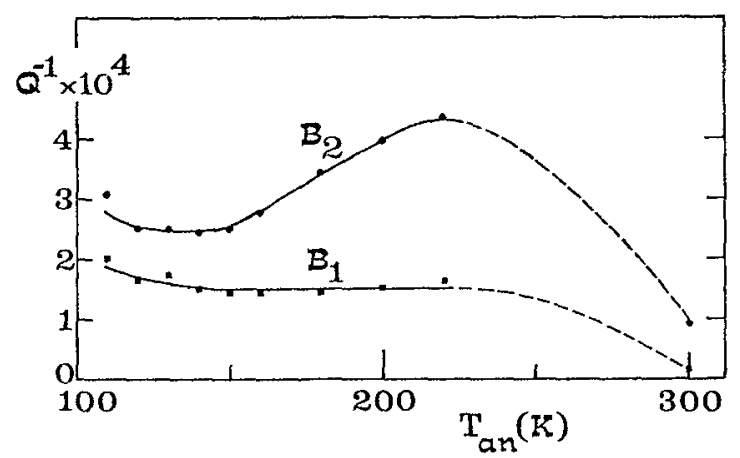

Fig. 4. Variation of the amplitudes of $\bar{B}_{1}$ and $B_{2}$ in a copper sample after isochronal annealings, versus the anneal temperature $\mathrm{T}_{\text {an }}$.

Fig. 5 shows the variation of the amplitude of $B_{2}$ in the silver sample, it increases between $150 \mathrm{~K}$ and $200 \mathrm{~K}$ and then decreases between $200 \mathrm{~K}$ and $300 \mathrm{~K}$. 
Fig. 5. Variation of the amplitude of $\mathrm{B}_{2}$ in a silver sample after irradiation at $110 \mathrm{~K}$ and subsequent isochronal annealings, versus the anneal temperature $\mathrm{T}_{\text {an }}$.

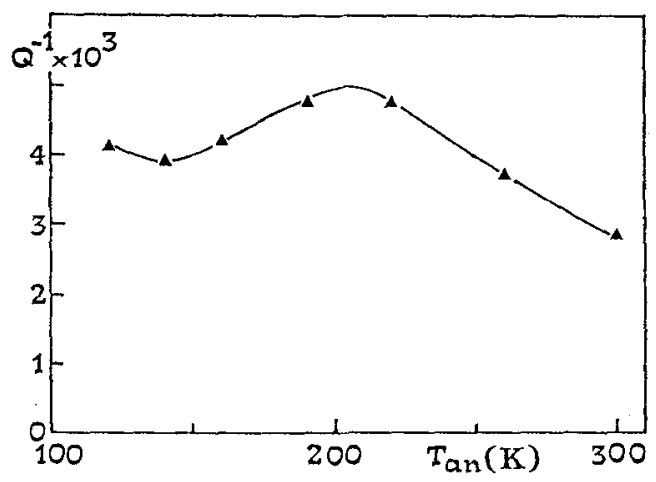

4. Interpretation.-

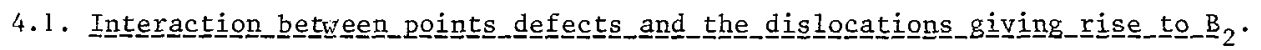
The behaviour of peak $B_{2}$ during irradiation and subsequent annealings is essentially the same in copper and silver samples and the interpretation is identical for the two metals.

Fig. 1 and 2 show that the amplitude of $B_{2}$ decreases continuously during irradiation at $110 \mathrm{~K}$, this usual behaviour is explained by the pinning of the dislocations giving rise to $B_{2}$ by the interstitials created by irradiation at $110 \mathrm{~K}$, the loop length between two pinning points decreases.

During successive annealings at increasing temperature, fig. 4 and 5 show an increase in the amplitude of $\mathrm{B}_{2}$ between 160 and $220 \mathrm{~K}$ in copper and 150 and $200 \mathrm{~K}$ in silver. Two principal interpretations can be proposed to explain the increase.

1) The arrival from the crystal of some defects which can eliminate a part of preexisting pinning points.

2) The elimination by diffusion along the dislocations of the pinning points which are the interstitiels created by irradiation at $110 \mathrm{~K}$.

We can throw out the first hypothesis for two reasons : the temperature range 150 to $220 \mathrm{~K}$ is too low to correspond to vacancy migration in the metals (4) (5) and in the same range the amplitude of $B_{1}$ does not vary. The second hypothesis explains very well the difference in the variations of $B_{1}$ and $B_{2}$.

The large pinning observed above $220 \mathrm{~K}$ in copper and $200 \mathrm{~K}$ in silver is connected to the arrival of monovacancies.

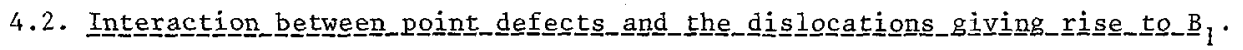

Fi. 1 shows that in copper the amplitude of $B_{1}$ begins to increase during irradiation for doses up to $2.10^{17} \mathrm{el} / \mathrm{cm}^{2}$ and then presents the expected decrease. During the bombardment only the length $L$ between pinning points can vary and all the theories indicate that the damping decreases when $\mathrm{L}$ decreases. We conclude that during the beginning of the irradiation at $110 \mathrm{~K}$ the interstitials arriving 
of the lines can diffuse and annihilate some preexisting vacancy type pinning points. When the dose increases further the interstitials can agglomerate or diffuse to geometrical kinks and if we assume that the agglomerates are stable and firmly pinn the dislocations, it is possible to explain the subsequent decrease of $B_{1}$ for higher doses.

Fig. 4 shows that during annealing between 110 and $220 \mathrm{~K}$ the amplitude of $\mathrm{B}_{1}$ remains constant, the decrease between 220 and $300 \mathrm{~K}$ is associated to a pinning by the monovacancies which migrate during stage III.

5. Conclusion.- These experiments can be explained with the hypothesis that the interstitials are stable on the dislocations giving rise to $\mathrm{B}_{2}$ (lying along <110>) up to $150 \mathrm{~K}$ in copper and silver and then can diffuse along them. In copper the interstitials can diffuse along the dislocations giving rise to $\mathrm{B}_{1}$ (1ying along $<112>$ for temperatures lower than $110 \mathrm{k}$. The vacancies pinn al1 the dislocation classes between 200 and $300 \mathrm{~K}$.

\section{References.-}

[1] J. Lauzier and C. Minier, this same congress.

[2] P. Girard, 1980, Thèse Universitê Scientifique et Međicale de Grenoble.

[3] J.C. Souliê, J.P. Jodeau, C. Minier and Y. Depierre, 1970, Rad. Effects, 11,221.

[4] C. Minier, M. Minier and R. Andreani, 1980, Phys. Rev. B, 22, 28.

[5] P.Hautojarvi, J. Johansson, A. Vehanen, J. Y1i-Kauppila, P. Girard and C. Minier: 1981, Journ. Phys. F, in press. 